ARTIGO

\title{
Inserção Social: em busca de sentidos e de indicadores para a avaliação da pós-graduação na área da Educação
}

Carlos Eduardo Ferraçoa Isabel Maria Sabino de Farias ${ }^{b}$

\section{Resumo}

O artigo problematiza o tema inserção social no processo avaliativo da pós-graduação stricto sensu em Educação no Brasil. Parte do exame da Ficha de Avaliação do quadriênio 2013-2016 para evidenciar como o quesito a inserção social está ali objetivado, análise cruzada com os debates decorrentes do I e II Seminários "O Sistema de Avaliação da Pós-Graduação Brasileira" promovidos pela Anped (2017 e 2018) e com dados de levantamento realizado na Plataforma Sucupira em 168 programas da área da Educação, no relatório anual de 2016, encaminhado pelos PPGE à Capes, das ações identificadas em suas práticas como objetivantes desse item. O que deve ser considerado neste quesito ainda é objeto de pouco consenso, agenda que se complexifica com as mudanças no Sistema de Avaliação da Capes, que propõe avaliá-lo a partir do seu impacto.

Palavras-chave: Inserção Social. Avaliação. Pós-Graduação. Educação.

\section{Introdução}

O artigo objetiva problematizar o tema inserção social na área da Educação, tendo como referência o processo avaliativo da pós-graduação em Educação no Brasil. Para isso, considera questões que surgiram tanto a partir das falas de coordenadores de diferentes programas que estiveram presentes no I e II

\footnotetext{
a Universidade Federal do Espírito Santo, Vitória, ES, Brasil.

b Universidade Estadual do Ceará, Fortaleza, CE, Brasil.
} 
Seminários ${ }^{1}$ "O Sistema de Avaliação da Pós-Graduação Brasileira”, ambos promovidos pela Associação Nacional de Pós-Graduação e Pesquisa em Educação (Anped), quanto por conta do que foi declarado no ano de 2016 na ficha de avaliação dos programas.

Por ocasião do I Seminário, foram organizados quatro grupos de trabalho para subsidiar a sistematização de um documentobase da Anped em torno de questões estratégicas para a pesquisa e a pós-graduação em Educação sustentáveis e de qualidade, quais sejam: a) política e financiamento;b) produção acadêmica;c) internacionalização; e d) inserção social. As análises registradas neste escrito vinculam-se a este último grupo.

O debate sobre o sistema de avaliação da pós-graduação tem mobilizado pesquisadores de todo o país (BALBACHEVSKY, 2005; BARRETO; BORGES, 2009; FERREIRA, 2018; HORTA; MORAES, 2005; SEVERINO, 2003; SGUISSARDI, 2009), evidenciando expressiva insatisfação da comunidade acadêmica com sua feição produtivista, característica que inibe a captação de elementos significativos do atual quadro de desenvolvimento da pós-graduação em Educação no Brasil, entre os quais se situam aqueles relacionados com a inserção social. Este quesito, relativamente recente na prática de avaliação dos programas de pós-graduação stricto sensu no Brasil, ao ser contemplado nesse processo, chama a atenção para a inter-relação "conhecimento e desenvolvimento, pesquisa e transformação social". Alguns autores consideram que essa medida foi uma redundância (BOUFLEUR, 2009), enquanto, para outros, significou um avanço no sistema de avaliação vigente (RIBEIRO, 2007).

Desde sua inclusão no formulário de avaliação da Coordenação de Aperfeiçoamento de Pessoal de Nível Superior (Capes), em 2007, o que deve ser considerado no quesito inserção social, ainda é objeto de pouco consenso e muitas dúvidas (VERHINE; DANTAS, 2009). As análises sistematizadas nesse documento, ao tentarem explicitar essa problemática, buscam contribuir para fazer avançar o delineamento desse quesito como objeto de avaliação.

Nesse sentido, o presentetexto está organizado emquatroseções. Examina-se, de início, a Ficha de Avaliação do quadriênio 2013-2016 para evidenciar como o

Ações desenvolvidas em articulação com o Fórum de Coordenadores de Programas de Pós-Graduação em Educação (Forpred), instância organizativa da Associação Nacional de Pós-Graduação e Pesquisa em Educação. O primeiro seminário foi realizado em Fortaleza, nos dias 4 e 5 de abril de 2017, e o segundo em Belo Horizonte, de 17 a 19 de setembro de 2018. Ambos tiveram a intenção de fomentar o debate sobre o tema e contribuir para a formulação de uma proposta para o Sistema Nacional de Avaliação da Pós-Graduação em Educação. 
quesito inserção social está ali objetivado. Na sequência, registra-se uma síntese das discussões ocorridas durante o Seminário em Fortaleza e, com base em levantamento realizado na Plataforma Sucupira em 168 programas da área da Educação, no relatório anual de 2016, destacam-se as ações identificadas pelos Programas de Pós-Graduação em Educação (PPGE) em suas práticas como objetivantes do item inserção social. A partir desse movimento de aproximação, discutem-se, por fim, alguns desafios e propostas de encaminhamentos relativos ao quesito inserção social na avaliação dos programas na área da Educação.

\section{Um olhar sobre a Ficha de Avaliação do quadriênio 2013-2016}

A ficha de avaliação adotada pela Capes é instrumento basilar à análise do quesito inserção social, uma vez que permite visualizar os aspectos dos quais derivam sua objetivação na prática dos programas de pós-graduação. O Documento de Área - Educação 2016 (CAPES, 2016) - traz as fichas de avaliação do quadriênio 2013-2016 destinadas aos programas acadêmico e profissional. Ao examiná-las, constata-se que: a) as duas fichas, no quesito inserção social, contemplam praticamente os mesmos itens, um total de três; b) distribuem, na mesma proporção, os pesos a todos os itens; c) valorizam o mesmo item, no caso o item 5.1, pontuando-o em 40\%; d) apresentam, como principal diferença entre programa acadêmico e profissional, o peso atribuído: $15 \%$ e 20\%, respectivamente. Os três itens considerados nas duas fichas de avaliação do quadriênio 2013-2016 são semelhantes, embora a terminologia adotada apresente pequenas alterações na formulação que deixam o texto mais conciso, mas não implicam, necessariamente, um conteúdo distinto. No Quadro 1, visualizam-se os três itens.

Quadro 1 - Detalhamento dos itens do quesito inserção social da ficha de avaliação dos programas acadêmico e profissional para o quadriênio 2013-2016

\begin{tabular}{|l|l|l|}
\hline Item/Programa & \multicolumn{1}{|c|}{ Programa Acadêmico } & \multicolumn{1}{|c|}{ Programa Profissional } \\
\hline Item 5.1 & $\begin{array}{l}\text { Inserção e impacto regional e/ou nacional } \\
\text { do programa }\end{array}$ & $\begin{array}{l}\text { Inserção e impacto local, } \\
\text { regional e/ou nacional } \\
\text { do programa }\end{array}$ \\
\hline Item 5.2 & $\begin{array}{l}\text { Integração e cooperação com outros } \\
\text { programas e centros de pesquisa e } \\
\text { desenvolvimento profissional relacionados } \\
\text { com a área de conhecimento do } \\
\text { programa, com vistas ao desenvolvimento } \\
\text { da pesquisa e da pós-graduação }\end{array}$ & $\begin{array}{l}\text { Integração e } \\
\text { cooperação com outros } \\
\text { cursos/programas com } \\
\text { vistas ao desenvolvimento } \\
\text { da pós-graduação }\end{array}$ \\
\hline Item 5.3 & $\begin{array}{l}\text { Visibilidade ou transparênciadada pelo } \\
\text { programa à sua atuação }\end{array}$ & $\begin{array}{l}\text { Visibilidade e transparência } \\
\text { da atuação do programa }\end{array}$ \\
\hline
\end{tabular}

Fonte: Documento de Área - Educação 2016 (CAPES, 2016) 
O Quadro 1 permite visualizar as alterações na formulação antes mencionadas. No item 5.1, o programa profissional minucia a abrangência da inserção e do impacto do programa, explicitando o âmbito local. Cabe frisar, entretanto, que, ao examinar o conteúdo declarado no relatório do quadriênio na Plataforma Sucupira, verifica-se que todos os programas, independentemente de serem acadêmico ou profissional, anotam atuações de abrangência local vinculadas ao contexto em que se encontram inseridos. No item 5.2, observa-se no programa acadêmico uma formulação mais pormenorizada em relação ao programa profissional, mas ambos guardam conotação similar. Considerações nessa mesma direção recaem sobre o item 5.3.

O teor da terceira coluna da ficha de avaliação, nomeada "Definições e Comentários sobre o Quesito/Itens", firma o argumento de semelhança, conforme realça o Quadro 2.

Quadro 2 - Coluna definições e comentários sobre o quesito/itens, por programa

\begin{tabular}{|c|c|c|}
\hline \multirow{2}{*}{$\begin{array}{l}\text { Item / } \\
\text { Programa }\end{array}$} & \multicolumn{2}{|c|}{ Definições e comentários sobre o quesito/Itens } \\
\hline & Programa Acadêmico & Programa Profissional \\
\hline Item 5.1 & $\begin{array}{l}\text { Impacto e inserção educacionais e } \\
\text { sociais do programa, assim como } \\
\text { seu impacto científico e tecnológico } \\
\text { Valorizar a produção de material } \\
\text { didático, parcerias com as redes } \\
\text { de Educação Básica, formação de } \\
\text { profissionais para os sistemas de } \\
\text { ensino, assessorias, projetos de } \\
\text { extensão, divulgação científica, } \\
\text { destinação dos egressos } \\
\text { Valorizar a participação em } \\
\text { sociedades científicas, organização } \\
\text { de eventos, criação de produtos e } \\
\text { processos tecnológicos entre outros }\end{array}$ & $\begin{array}{l}\text { Perspectiva de atuação } \\
\text { profissional do egresso } \\
\text { Demonstração da formação de parcerias } \\
\text { com as Redes Municipal, Estadual, } \\
\text { Federal e/ou com outros espaços de } \\
\text { atuação dos profissionais da Educação } \\
\text { Organização de eventos, atividades de } \\
\text { intervenção e ações de formaçãode } \\
\text { profissionais da Educação } \\
\text { Descrição dos impactos alcançados pelo } \\
\text { programa, considerando as dimensões: } \\
\text { impacto social/educacional; impacto } \\
\text { profissional; impacto artístico/cultural; } \\
\text { impacto tecnológico; entre outros }\end{array}$ \\
\hline Item 5.2 & $\begin{array}{l}\text { Integração e solidariedade com } \\
\text { outros programas/instituições, } \\
\text { valorizando a sinstituições } \\
\text { estrangeiras e aquelas de maior } \\
\text { duração e impacto }\end{array}$ & $\begin{array}{l}\text { Evidências da participação em } \\
\text { programas de cooperação e } \\
\text { intercâmbios na área de Educação } \\
\text { Evidências da cooperação entre } \\
\text { programas da modalidade profissional } \\
\text { em busca de consolidação stricto sensu }\end{array}$ \\
\hline
\end{tabular}

Continua 
Continuação

\begin{tabular}{|c|c|c|}
\hline Item 5.3 & $\begin{array}{l}\text { Atualização e manutenção do site } \\
\text { do programa } \\
\text { Divulgação das teses e dissertações, } \\
\text { resguardadas as situações em que } \\
\text { o sigilo deve ser preservado (Art. } 2^{\circ} \text {, } \\
\text { Portaria Capes } n^{\circ} 13 / 2006 \text { ) } \\
\text { Visibilidade das atividades, } \\
\text { projetos, produções e impactos dos } \\
\text { grupos de pesquisa que constituem } \\
\text { os programas } \\
\text { Visibilidade das produções } \\
\text { e produtos mais relevantes } \\
\text { do programa } \\
\text { Espaços de divulgação científica } \\
\text { e difusão de conhecimentos/ } \\
\text { tecnologias produzidos com } \\
\text { os profissionais das áreas de } \\
\text { concentração dos programas }\end{array}$ & $\begin{array}{l}\text { Atualização e manutenção do } \\
\text { site do programa } \\
\text { Divulgação dos trabalhos de conclusão } \\
\text { de curso, resguardadas as situações em } \\
\text { que o sigilo deve ser preservado (Art. } 2^{\circ} \text {, } \\
\text { Portaria Capes n¹3/2006) } \\
\text { Visibilidade das atividades, projetos, } \\
\text { produções e impactos dos grupos de } \\
\text { pesquisa que constituem os programas } \\
\text { Visibilidade das produções e produtos } \\
\text { mais relevantes do programa } \\
\text { Espaços de divulgação científica e } \\
\text { difusão de conhecimentos/tecnologias } \\
\text { produzidos com os profissionais das } \\
\text { áreas de concentração dos programas }\end{array}$ \\
\hline
\end{tabular}

Fonte: Documento de Área - Educação 2016 (CAPES, 2016)

Como a própria designação da coluna indica, seu propósito é tornar mais nítida a objetivação de cada item. Pelos aspectos realçados no Quadro 2, averíguam-se os alinhamentos em relação ao que deve ser incluído como práticas que evidenciem o compromisso social do programa. Nota-se no item 5.3, por exemplo, que a redação é igual, exceto no tópico que faz referência à característica peculiar do trabalho produzido em cada programa - dissertações e teses no programa acadêmico, trabalhos de conclusão de curso no programa profissional- mantendo, portanto, o mesmo sentido.

O item 5.2 traz uma formulação aparentemente distinta entre os programas acadêmico e profissional; aparentemente porque os aspetos objetivados guardam uma conotação similar. Enquanto a formulação, no âmbito do programa acadêmico, dá relevo à abrangência das ações/atividades de integração e solidariedade, hoje tacitamente identificadas como comprobatórias da consolidação da atuação no nível stricto sensu, o programa profissional aponta para essas mesmas ações/atividades de modo mais focalizado. O programa profissional reporta-se, ainda, a "evidências" de cooperação e intercâmbio entre programas da área (ou seja, de integração mais geral) e de cooperação entre programas profissionais, visando a firmar essa modalidade no âmbito da oferta stricto sensu nacional (ou seja, de solidariedade interna).

No item 5.1, o que se observa é uma formulação mais globalizante dos aspectos no programa acadêmico. No programa profissional, aparecem de modo mais 
detalhado e listados em outra sequência. Por exemplo, o que no programa acadêmico está formulado como "Impacto e inserção educacionais e sociais do programa, assim como seu impacto científico e tecnológico" encontra-se anotado no programa profissional como "Descrição dos impactos alcançados pelo programa, considerando as dimensões: Impacto social/educacional; Impacto profissional; Impacto artístico/cultural; Impacto tecnológico; Outros impactos". Nessas duas formulações, o elemento definidor do aspecto a ser considerado mantém-se: o impacto da atuação do programa.

A parceria com as redes de ensino, a atuação na formação de profissionais da Educação, a organização de eventos e a destinação dos egressos são elementos comuns claramente explicitados nas duas modalidades de programas no item 5.1. No programa acadêmico constam, ainda, referências diretas a assessorias, projetos de extensão, divulgação científica, participação em sociedades científicas, criação de produtos e processos tecnológicos, entre outros. Embora não pormenorize nos mesmos termos, o programa profissional prevê tanto a " [...] organização de [...] atividades de intervenção [quanto a] demonstração [...] de outros espaços de atuação dos profissionais da Educação", deixando em aberto as possibilidades de objetivação da inserção e impacto de sua prática.

Essas aproximações autorizam afirmar que não há diferenciação nos itens que objetivam a inserção social na ficha de avaliação adotada pela Capes, tanto no programa acadêmico quanto no programa profissional. O que isso evidencia?

A similitude dos aspectos objetivados nos três itens que compõem a avaliação do quesito inserção social pode ser entendida como um indicativo de atividades com potencial de evidenciar o vínculo e o impacto dos programas com a sociedade, num círculo virtuoso entre prática, pesquisa e formação e, ao mesmo tempo, como uma expressão de que o que define a inserção social não varia (não é diferente) em decorrência da modalidade/natureza do programa, se acadêmico ou profissional. Sendo assim, o que se verifica, tal como objetivado na ficha de avaliação para o quadriênio 2013-2016 (CAPES, 2016), é o reforço do argumento da inserção social como uma dimensão constitutiva do fazer da pós-graduação (BOUFLEUER, 2009), seja ela acadêmica, seja profissional.

\section{Indicativos do debate sobre inserção social nos Seminários I e II}

O trabalho em grupos, como já assinalado, foi uma das atividades previstas no I Seminário "O Sistema de Avaliação da Pós-Graduação Brasileira", evento realizado 
visandoa promover o debate acerca de assuntos centrais e delicados para apesquisa e a pós-graduação emEducação no país, entre os quais se encontra o tema inserção social.

A discussão efetuada pelos participantes do GT Inserção Social, em Fortaleza, por diversas vias, tende a corroborar o argumento da Educação como um bem público (SGUISSARDI, 2009) e, por conseguinte, da inserção social como parte constitutiva do fazer da pós-graduação (BOUFLEUER, 2009; JEZINE; FERREIRA, 2016), ou seja, está pressuposto, pois faz parte do fazer universitário. Republicanamente, isso implica a existência de uma responsabilidade pública e de uma finalidade social por parte das instituições de Educação, entre elas, a universidade. Sob essa ótica, a inserção social não é uma ação estanque e pontual, mas uma ação orgânica à função da pós-graduação.

Nesse sentido, retomam-se as ponderações de Boufleuer (2009) sobre a inserção social como quesito no âmbito da avaliação da pós-graduação, por entender que elas podem contribuir para fazer avançar a compreensão e o debate. Os excertos, embora longos, são provocativos:

Mais do que quantidade, percentuais disso ou daquilo, trata-se de avaliar a capacidade de um programa, explicitar a forma como articula em seu âmbito a contínua modificação do conhecimento, a formação dos profissionais e as demandas de transformação social. Essa capacidade autorreflexiva deve vir acompanhada, obviamente, da indicação de ações pontuais ou continuadas, condizentes com o tamanho do programa e a respectiva área de conhecimento[...].Tornase fundamental o olhar do próprio programa. [...] o mesmo deverá explicitar como compreende a presença dessa dimensão de inserção social no conjunto de suas atividades [...].

E isso pode ser objeto de avaliação, nos mesmos termos em que faz parte da avaliação a capacidade de um programa explicitar a sua proposta [...]. O que se está sugerindo, por isso, é que o quesito inserção social seja avaliado de forma análoga à avaliação do quesito 'proposta do programa', com a diferença de que será pontuado [...] (BOUFLEUER, 2009, p.380-381).

As proposições acima apontam para um quesito que possibilitaa cada programa, de modo coerente com seus objetivos e estrutura, "dizer de si", ou, em outros termos, evidenciar a abrangência de sua atuação espaço-temporal, suas especificidades e suas diferenças regionais e locais, mediante o detalhamento das ações realizadas, 
de sua periodicidade, continuidade, abrangência e articulação com políticas mais amplas. Ecos dessa proposição podem ser identificados desde a avaliação dotriênio 2010-2012, que trouxe nas orientações sobre os quesitos "Proposta do Programa" e "Inserção Social" a referência de que se trata de um "indicador de natureza qualitativa", tratamento adotado nas duas modalidades de programa - acadêmico e profissional.

A adoção de peso é o elemento distintivo no tratamento dispensado aos quesitos Proposta do Programa e Inserção Social, instigando a problematização desse procedimento. A questão a ser enfrentada, ao que parece, é se, de fato, é necessário ter uma regulação externa para fazer com que os programas desenvolvam sua responsabilidade social. Afinal, ao considerar a inserção social como constitutiva, portanto, imbricada com a forma como o programa estrutura-se e com o que ele faz, por que pontuá-la? Em que essa regulação favorece o delineamento da inserção social como quesito avaliativo qualificador da pós-graduação? Essas, por certo, são questões a se enfrentar sob o risco de, por um lado, negar a qualidade da contribuição social da pós-graduação para o desenvolvimento e para a transformação da sociedade; e, por outro, reforçar a tendência à integração entre produção do conhecimento e do mercado (JEZINE; FERREIRA, 2016).

\section{Um olhar por dentro dos programas: o que conta como inserção social?}

Que ações os PPGE associam ao item inserção social no relatório de avaliação da Plataforma Sucupira? Esse questionamento foi movidopela necessidade de se conhecer mais sobre a expressão desse componente avaliativo na prática declarada pelos programas, considerando a objetivação explicitada na ficha de avaliação da área. A demanda aflorou ainda em Fortaleza, instigada pelos relatos registrados na ocasião, quando se averiguou uma multiplicidade de ações anotadas no quesito inserção social.

Como olhar para dentro de uma área de tamanha abrangência? A realização de um exame das informações do relatório contido na Plataforma Sucupira divisou-se como uma alternativa, o que foi realizado considerando os dados do relatório anual de 2016encaminhado pelos programas à Capes (ANPED, 2017). Para realizar essa aproximação recorreu-se ao software de análise de dados qualitativos QSR NVivo10 (CAVALCANTE; GUIMARÃES; MENDES, 2016; LAGE, 2011), utilizando-o na organização e tratamento dos dados declarados pelos $168 \mathrm{PPGE}^{2}$, de modo

\footnotetext{
Foram identificados 168 dos 172 programas, pois quatro eram mais recentes e não dispunham de relatório. Também havia programas em rede cujo conteúdo era semelhante, sendo incluído somente uma vez. Ao final, foi organizado um conjunto de arquivos nomeados individualmente com um código que permite identificar instituição e programa. Esses arquivos constituem as fontes armazenadas no software.
} 
a buscar identificar o conteúdo relacionado, pelos programas, com a inserção social. Concluída essa etapa, procedeu-se à leitura do conteúdo de cada arquivo, buscando identificar as ideias recorrentes, posteriormente aglutinadas em torno de um tema ou bloco temático. Ao todo foram definidos dez blocos temáticos:

a) Contextualização e aspectos gerais do programa;

b) Perspectivas do programa sobre inserção social;

c) Contribuição do programa para a formação de docentes das IES e Educação Básica;

d) Interface com a Educação Básica;

e) Produções do corpo docente e discente;

f) Parcerias e convênios visando a ações de pesquisa, ensino e extensão;

g) Atividade de difusão do conhecimento;

h) Atividade de inserção política, administrativa e acadêmica;

i) Atividade de gestão acadêmica;

j) Premiações e homenagens.

Ao considerar como os programas buscam dar visibilidade às ações objetivantes do item inserção social, observou-se, de início, uma preocupação em contextualizar o programa, preocupação expressa na explicitação de informações que o situam no cenário geopolítico do país, com dados sobre o processo seletivo, a oferta e a demanda, as defesas realizadas, além de destaques a algum traço percebido pelo programa como um diferencial.

A crescente demanda de candidatos no processo seletivo, a procura e a participação de estudantes de outras universidades na condição de alunos especiais, a indicação de egressos que se encontram dando continuidade aos estudos pós-graduados, a inserção de egressos na docência na Educação Superior e na Educação Básica, a criação de novos grupos de pesquisa sobre temáticas estudadas durante a formação $\mathrm{e}$, até mesmo, o credenciamento de professores advindos de outros campi e outros 
municípios onde a universidade está inserida são algumas outras informações que dão o tom aos elementos contextuais registrados pelos programas. É nítida a intenção de mostrar a identidade do programa e, ao evidenciar suas peculiaridades, desvelar como a inserção social objetiva-se nessa identidade.

Outro aspecto que chama a atenção, refere-se à necessidade de explicitar a perspectiva do programa sobre inserção social, isto é, como cada programa entende e pratica a inserção social. Aliás, aqui um primeiro destaque reporta-se à identificação de registros sobre a natureza transversal deste quesito. A necessidade constante de retomada de informações já apresentadas em outros itens da ficha de avaliação, a nosso ver, reforça o argumento sobre a transversalidade da inserção social e, em última instância, desta como uma dimensão constitutiva do fazer da pós-graduação.

A categoria "perspectiva do programa sobre inserção social" agregou referências amplas acerca da compreensão do quesito e que aludem sobre como ele é objetivado na atuação do programa. Assim, fica evidente um movimento de diálogo com o quesito avaliativo inserção social, realizado com o objetivo de clarificar a compreensão que move a prática institucional dos programas, associando-a à sua objetivação e a uma variedade de possibilidades de frentes de atuação.

A referência à contribuição do programa para a formação de docentes, seja na Educação Básica, seja na Educação Superior, sobressai nos registros dos relatórios do ano de 2016 da Plataforma Sucupira, entendida como decorrência orgânica à área à qual o programa está vinculado e aos objetivos institucionais. Nesse sentido, os programas asseveram manter forte interface com a Educação Básica. São inúmeras e diversificadas as atividades desenvolvidas e que tornam concreta essa articulação, contemplando: ações de formação continuada de curta, média e longa duração, em particular cursos de especialização; participação em bancas de concurso e em comissões de avaliação de abrangência local, regional e nacional; realização de palestras, entrevistas, conferências, oficinas e minicursos, tendo como principal público-alvo professores e profissionais da Educação em geral; coordenação e/ou atuação como docente em programas governamentais voltados para a formação de professores.

Além disso, também são contempladas pesquisas sobre a escola e os professores, bem como a participação de professores da escola em pesquisa e grupos de estudo e pesquisa na universidade; atuação dos docentes do programa em cursos de formação inicial, presencial, a distância e em diferentes áreas do conhecimento, os quais atendem à parcela expressiva de professores inseridos na rede de 
Educação Básica; articulação dos pós-graduandos durante o estágio de docência com graduandos professores que trabalham na escola; criação programas de rádio, de blogs, páginas e chats, bem como de fóruns virtuais e presenciais e, ainda, diversas propostas de projetos de intervenção. Soma-se a esse conjunto um amplo leque de ações extensionistas.

Medidas para apoiar o ingresso na pós-graduação, a exemplo da isenção de taxas no processo seletivo e da articulação com Secretarias de Educação, visando à concessão de licenças e bolsas para professores cursarem mestrado ou doutorado, também foram anotadas. Para além de um inventário pormenorizado, sublinhase a riqueza das possibilidades desenhadas de objetivação do compromisso da pós-graduação com o conhecimento e a transformação da realidade social, em particular com os desafios da Educação Básica.

Asproduções bibliográficas de docentes e de discentes também são anotadas como ação objetivadora da inserção social do programa, expressão, aliás, bastante recorrente. Verificou-se o cuidado em explicitar a relevância de cada produção a partir de sua vinculação a projetos de extensão e/ou de pesquisa desenvolvidos no âmbito do programa, bem como sua interface com a Educação Básica.

Nessa mesma linha, são destacadas produções técnicas diversas, desde a elaboração de documentos e textos para a rede até cartilhas, cadernos, kits de materiais didáticos para uso escolar e/ou processos de formação, livros didáticos ligados a programas nacionais, vídeos documentários, bancos de dados, livros paradidáticos, propostas de cursos on-line, museus virtuais e software interativo para uso pedagógico de professores, de alunos e de mediadores culturais. Em geral, no registro das produções bibliográficas e técnicas,destaca-se ora a participação dos professores do programa, ora desses com discentes da pós-graduação e com professores da Educação Básica, anotando-se, ainda, que elasresultam do trabalho articulado no âmbito das linhas e dos grupos de pesquisa.

Múltiplos também são os apontamentos acerca de parcerias e/ou convêniosvisando à efetivação de ações de pesquisa, ensino e de extensão, tanto em âmbito nacional quanto internacional. Além da forte interface com as Secretarias de Educação e as redes de ensino, aqui também sobressaem referências a intercâmbios com outras universidades, institutos, grupos de pesquisa e outros programas de pós-graduação.

Atividades voltadas para a difusão do conhecimento também são anotadas como ações objetivadoras da inserção social dos programas de pós-graduação, especialmente organização e participação em evento, desenvolvimento de sites, 
blogs e revistas. A organização de eventos aparece como carro-chefe desse tipo de atividade, que apresenta abrangência variada (de internacional a local) e diferentes modalidades, desde encontros, reuniões científicas, seminários, colóquios, jornadas, debates, feiras, diálogos/conversas, workshops, semanas culturais, mostra de ciência, ciclo de estudos, fóruns, simpósios, congressos, apenas para citar os registros mais recorrentes. Ao lado da organização, a participação em evento, sobretudo como palestrante ou responsável por minicursos e oficinas, ganha importância como atividade que objetiva a inserção social dos programas na área. Outra ação realçada é a criação e a manutenção de páginas, sites,blogs e jornais on-line, além da edição e da publicação de periódicos indexados.

Ainda no que concerne à inserção social científica por meio da difusão do conhecimento, destacam-se a criação e/ou o desenvolvimento de espaços interculturais que propiciam acesso maior a diferentes segmentos sociais, como casas de cultura, museus itinerantes e festivais; estes, com menor recorrência. Importante frisar que a articulação entre pesquisadores, instituições nacionais e internacionais de pesquisa, graduação, pós-graduação e as redes de Educação Básica dá o tom às práticas mencionadas que, no âmbito do quesito inserção social, buscam dar visibilidade à difusão do conhecimento, em uma perspectiva científica, informativa ou de formação.

Outra expressão das ações anotadas pelos programas de pós-graduação, como evidenciadora de sua capacidade de articulação e de compromisso com a sociedade a partir da função que lhe é própria, encontra-se no desenvolvimento de atividades de inserção política, administrativa e acadêmica. Estas compreendem ações de representação, marcadas especialmente pela atuação em comitês científicos de eventos, conselhos editoriais e parecerista $a d$ hoc de periódicos qualificados, assessoria e consultoria a agências de fomento à pesquisa e órgãos governamentais.

As ações detalhadas nos relatórios evidenciam a capilaridade dos programas em diversos contextos e situações da agenda educativa nacional, ressaltando a atuação de seus professores em várias frentes, a circulação e o reconhecimento pelos pares, bem como a integração e a disseminação de técnicas e de conhecimentos que qualificam práticas afeitas ao campo. É nessa direção também que atividades de gestão acadêmica são indicadas como expressão objetivadora da inserção social no cotidiano do fazer da pós-graduação, incluindo desde a coordenação de pesquisa, de programas e de projetos institucionais e governamentais, de laboratórios e de grupos de pesquisa, de cursos de graduação e de extensão, até o exercício de cargos na gestão da universidade. 
Denota-se das referências o reconhecimento de que as atividades de gestão acadêmica oportunizam uma interlocução com a comunidade acadêmica interna e externa à universidade, retroalimentando-as. Foram identificados, ainda, registros de premiações, homenagens e títulos públicos de ampla visibilidade social, como o Prêmio Jabuti, o Prêmio Cora Coralina (Anped), a Homenagem Paulo Freire (Anped), a concessão de títulos de cidadania e de Professor Emérito, além de concursos científicos promovidos em eventos universitários, como ações que evidenciam a inserção social no âmbito das práticas de pesquisa e de formação que sustentam a pós-graduação.

enfim, o inventário das ações declaradas pelos programas de pós-graduação como objetivantes da inserção social na área mostra uma variedade de possibilidades produzidas de modo articulado com as peculiaridades de cada contexto e a expertise do corpo docente, dos grupos e das linhas de pesquisa instaladas. Essa variedade revela diversidade, riqueza e criatividade no sentido de gerar respostas às expectativas sociais, sejam locais, sejam mais amplas.

\section{Desafios que permanecem e algumas propostas de encaminhamentos}

Grosso modo, o presente artigo buscou um delineamento geral dos sentidos e das ações de inserção social que vêm se constituindo na área da Educação e, ainda, de possíveis indicadores que pudessem propiciar sua objetivação na avaliação dos PPGE no país.

Foi nessa direção que se aludiu à busca de sentidos da ação de inserção social dos PPGE, ou seja, a área necessitava, e ainda necessita, posicionar-se de modo a explicitar referências conceituaisque possam fundamentar sua avaliação pela Capes. Referências constituem, portanto, balizadores que possibilitem compreender e ajuizar, em uma perspectiva qualitativo-formativa, diferentes tipos de ações que compõem e informam a dimensão da inserção social desenvolvida pelos programas da área.

A emergência histórica da inserção social na avaliação da pós-graduação foi impulsionada pelo entendimento de que ela deveria possibilitar aos programas, de maneira coerente com seus objetivos, metas e estrutura, "dizer de si", ou, em outros termos, evidenciar a abrangência de sua atuação espaço-temporal, suas especificidades e suas diferenças regionais e locais, mediante o detalhamento das ações realizadas, de sua periodicidade, continuidade, abrangência e articulação com políticas mais amplas. Posto isso, é preciso considerar que não há inserção 
social melhor ou pior. Como requisito avaliativo que possibilite inferências sobre a qualidade dos cursos a partir de sua ação formadora, de pesquisa e de produção de conhecimento, é de fundamental importância caracterizar e registrar a inserção social como uma ação orgânica à função e às peculiaridades de cada programa de pós-graduação.

O Documento de Área da Educação é silencioso na explicitação da acepção de inserção social que adota como referência, o que favorece o atravessamento de diferentes acepções e compreensões em torno deste quesito, como foi possível constatar na análise dos relatórios dos programas. Com isso, o que deve ser considerado, ou não, como inserção social, no âmbito da pós-graduação em Educação no Brasil, permanece ainda objeto de pouco consenso e muitas dúvidas. Os indicativos do debate na área registram sobreposição de informações no quesito inserção social em relação a outros quesitos/itens, em particular no que concerne à interface com a Educação Básica. Distintamente das demais áreas, prevalece o reconhecimento de que essa interface é intrínseca à Educação.

O inventário das ações declaradas pelos PPGE na Plataforma Sucupira como objetivantes da inserção social na áreamostrou grande variedade, produzidas em articulaçãocom as peculiaridades de cada contexto e a expertise do corpo docente, dos grupos e das linhas de pesquisa instalados, revelando diferenças, diversidades, riquezas e criatividade na produção de respostas às expectativas sociais, locais, regionais ou mais amplas.

As discussões encaminhadas a partir do exame das ações declaradas pelos PPGE em 2016, em linhas gerais, evidenciam tratar-se de um conceito amplo e, ao mesmo tempo, multifacetado que se funde e se complexifica, como já observado, na interrelação entre conhecimento, pesquisa, desenvolvimento e transformação social. Nestes termos, tende a prevalecer na área uma compreensão de inserção social que a associa a um conceito que possibilita inferências sobre o impacto político e social dos cursos, considerando sua ação formadora e de produção de conhecimento. Entende-se que tais inferências articulam-se com as peculiaridades de cada programa, abrangendo ações em diferentes contextos (locais, regionais ou nacionais) e com temporalidade variada (imediata, em médio ou em longo prazo).

Esse entendimento contrapõe-se à ideia de inserção social como ação estanque e pontual, firmando a dimensão do coletivo, de modo a favorecer uma noção de inserção social que possibilitea cada programa, coerentemente com seus objetivos e sua estrutura, evidenciar a abrangência de sua atuação espaço-temporal, de suas diferenças, especificidades e diversidades regionais e locais, mediante o 
detalhamento das ações realizadas, de sua periodicidade, continuidade, abrangência e articulação com políticas educacionais mais amplas. Evidência, aliás, que remete àquele sentido de inserção social destacado no começo deste escrito, qual seja, inserção social como ação orgânica à função da pós-graduação, à sua área de concentração, às suas linhas e seus projetos de pesquisa e com uma feição intencional, planejada e multifacetada em sua objetivação na prática dos PPGE.

Sobre esse aspecto, importa realçar que, ao mesmo tempo em que se percebe, nas ações declaradas pelos programas, uma tentativa de fazer da inserção social uma ação orgânica e articuladora dos seus objetivos e linhas de pesquisa, também evidencia-se certa prática de fragmentação das informações, em boa medida impulsionada pelo modo estruturado e concorrencial como o quesito está delineado no próprio documento do processo avaliativo da Capes.

Obviamente, diluir a inserção social em ações pontuais e imediatas não favorece uma compreensão da dimensão orgânica da interrelação entre conhecimento, desenvolvimento, pesquisa e transformação social, fulcro do quesito inserção social. Com isso, a tentativa de se buscar pactuar um entendimento de inserção social para a área de Educação constitui-se como um desafio estruturante e permanente, pois as dúvidas que surgem na hora de preencher a avaliação e, por efeito, alguns dos problemas identificados após o resultado, decorrem, justamente, da dispersão de seu significado.

Desse modo, para avançar em relação à constituição de sentido para a inserção social como componente de avaliação da pós-graduação stricto sensu, é primordial que o Documento de Área (no caso, o da Educação), que é balizador desse processo, deixe claro o que entende por esse quesito, uma vez que o termo inserção social tende, em alguns discursos, a ser reduzido a uma perspectiva genérica e asséptica. Isso tem favorecido, nos diferentes segmentos e contextos, de maneira explícita ou latente, desde os representantes da Capes aos coordenadores de programa, gestores educacionais, pesquisadores e público em geral, que cada programa assuma uma concepção particular de inserção social. Tal dispersão é problemática, sobretudo quando presente em uma prática avaliativa, o que sinaliza para a necessidade de se pactuar um entendimento de inserção social para a área de Educação.

Pactuar, nesses termos, implica considerar as diferenças na expectativa de, na medida do possível, construir acordos e estabelecer parâmetros, isto é, instituir um "comum", não como um a priori, mas como um efeito da diferença a ser tomado como referência para a avaliação. Medida necessária porque, para ocoletivo institucional dos programas, dispor de uma orientação explícita e direta 
sobre a expectativa em torno do qual o quesito inserção social será avaliado faz diferença. Possibilitará, entre outros aspectos, reduzir tanto as dúvidas e os problemas decorrentes, por exemplo, de sobreposição de informações, quanto de sua pulverização, na medida em que essa orientação esclarece sobre as prioridades nesse quesito. Tais prioridades, a nosso ver, encontram sua pertinência naárea de concentração e nas linhas de pesquisa do programa.

O documento sistematizado pela Anped (2018), apresentado e discutido no II Seminário "O Sistema de Avaliação da Pós-Graduação Brasileira" (2018, BH/ MG), cujas formulações estão sintetizadas neste texto, contribui nessa direção ao proporquatro dimensões norteadoras para a avaliação da inserção social, anotadas no Quadro 3.

Quadro 3 - Proposta de dimensões a serem consideradas no processo avaliativo da Capes em relação ao quesito inserção social

\begin{tabular}{|c|c|}
\hline $\begin{array}{c}\text { Principais evidências do levantamento } \\
\text { sobre inserção social na prática dos } \\
\text { programas (Anped, 2017) }\end{array}$ & $\begin{array}{l}\text { Proposta de dimensões/eixos } \\
\text { estruturantes (Anped, 2018) }\end{array}$ \\
\hline Preocupação em contextualizar o programa & $\begin{array}{l}\text { Contextualização e interlocução da } \\
\text { proposta do programa com as demandas }\end{array}$ \\
\hline $\begin{array}{l}\text { Contribuição do programa para a formação } \\
\text { de docentes }\end{array}$ & \multirow[t]{2}{*}{ Formação humana } \\
\hline Interface com a Educação Básica & \\
\hline Produção bibliográfica & \multirow{4}{*}{ Produção e circulação de conhecimentos } \\
\hline Produções técnicas & \\
\hline Organização de eventos & \\
\hline Participação em eventos & \\
\hline $\begin{array}{l}\text { Parcerias e/ou convênios, } \\
\text { intercâmbio, consultoria }\end{array}$ & \multirow{2}{*}{$\begin{array}{c}\text { Atuação acadêmica, administrativa } \\
\text { e política }\end{array}$} \\
\hline $\begin{array}{l}\text { Atividades de inserção política, } \\
\text { administrativa e acadêmica }\end{array}$ & \\
\hline
\end{tabular}

Fonte: Documento Anped (2018)

O Quadro 3 permite perceber que as quatro dimensões propostas pelo Grupo de Trabalho da Anped/Forpred, que discutiu a temática nos anos de 2017 e de 2018, decorrem das constatações do levantamento realizado no relatório anual de 2016, encaminhado pelos programas à Capes. Desse modo, mesmo preliminarmente, é possível inferir que, para a área de Educação,o quesito inserção social seria composto por quatro dimensões (ou sustentado por quatro eixos estruturantes) que se interrelacionam, guardando suas especificidades. 
Em frente às discussões até aqui realizadas, reafirma-se a inserção social como elemento importante do trabalho da pós-graduação stricto sensu em Educação no Brasil. De igual maneira, argumenta-se que sua conceituação e avaliação, para extrapolar uma abordagem meramente quantitativa, requer uma revisão urgente dos critérios e dos procedimentos empregados. Em termos práticos, faz-se urgente e necessário: a) estabelecer as ênfases/prioridades que a área tenha interesse em induzir/fomentar; b) rever os indicadores de cada item (as ações) da ficha de avaliação a partir das ênfases/prioridades delineadas para a área; c) construir uma escala que permita objetivar a avaliação qualitativa do quesito inserção social; d) explicitar, no Documento de Área, orientações acerca das ênfases/prioridades, dos aspectos a serem destacados nas ações registradas pelos programas e da métrica que será utilizada para avaliar o quesito.

Essa é uma agenda que se torna complexa no atual contexto sociopolítico nacional, em que mudanças no Sistema de Avaliação da Capes estão previstas, as quais situam a inserção social em um lugar diferente do ocupado até então no documento de avaliação. Pelo que tudo indica, a nova sistemática de avaliação terá apenas três itens (proposta do programa, formação e impacto) e não mais os cinco que vigoraram até então (proposta do programa, corpo docente, corpo discente, teses e dissertações e produção intelectual).

Na proposta em discussão no atual quadriênio (2017-2020), a inserção social comporia o item impacto, juntamente com os outros itens restantes. Ou seja, a inserção social seria avaliada a partir do seu impacto. Para além das mudanças acenadas, permanece o desafio: como avaliar, objetivamente, o impacto de uma ação de inserção social, mesmo que ela tenha sido prevista pelo próprio programa? Certamente não seria verificando se a referida ação foi ou não realizada. Pensamos que, mais uma vez, esbarramos na necessidade de identificação de descritores que possam objetivar quantitativa e qualitativamente as ações de inserção social. Questões, por certo, ainda a enfrentar. 


\title{
Social Insertion: in search of senses and indicators for the evaluation of post-graduation in the Education area
}

\begin{abstract}
The article problematizes the theme social insertion in the evaluative process of Stricto Sensu post-graduation in Education in Brazil. From the examination of the Assessment Form of the quadrennium 2013-2016, it shows how the social insertion question is there objectified, triangulated analysis with the debates arising from the I and II Seminars "The Brazilian Postgraduate Evaluation System” promoted by ANPED (2017 and 2018) and with data obtained from the Sucupira Platform in 168 education programs, in the 2016 annual report sent by the PPGEs to Capes, of the actions identified in their practices as concretizers of this item. What should be considered in this regard is still the subject of little consensus, an agenda that becomes more complex with changes in the Capes Evaluation System, which proposes to evaluate it based on its impact.
\end{abstract}

Keywords: Social Insertion. Evaluation. Postgraduate studies. Education.

\section{Inserción social: en busca de significados e indicadores para la evaluación de los Estudios de Posgrado en el campo de la Educación}

\section{Resumen}

El artículo discute el tema de la inclusión social en el proceso de evaluación del Programa de Posgrado en Educación Stricto Sensu en Brasil. Parte del examen del Formulario de Evaluación para el cuatrienio 2013-2016 para mostrar cómo se plantea la cuestión de la inserción social, análisis cruzado con los debates surgidos en el $1^{\circ}$ y $2^{\circ}$ Seminarios "El Sistema de Evaluación de los Posgrados Brasileños" promovido por ANPED ( 2017 y 2018) y con datos de la encuesta realizada en la Plataforma Sucupira en 168 programas del campo de la Educación, en el informe anual de 2016, enviado por los PPGE a Capes, de las acciones identificadas en sus prácticas como puntuales de este item. Lo que se debe considerar al respecto sigue siendo tema de poco consenso, una agenda que se vuelve más compleja con los cambios en el Sistema de Evaluación de Capes, que propone evaluarlo en función de su impacto.

Palabras clave: Inserción social. Evaluación. Posgraduación. Educación. 


\section{Referências}

ANPED. Inserção social: em busca de sentidos e indicadores para a avaliação da Pós-Graduação na área da Educação. In: SEMINÁRIO O SISTEMA DA AVALIAÇÃO DA PÓS-GRADUAÇÃO BRASILEIRA, 2., 2018, Belo Horizonte. Rio de Janeiro, Anped, 2018. Disponível em: https://anped.org.br/sites/default/files/images/gt_insercao_social.pdf. Acesso em: 5 jul 2019.

ANPED. Inserção social nos programas de Pós-Graduação em Educação: apontamentos para o debate. In: FÓRUM DE COORDENADORES DE PROGRAMAS DE PÓS-GRADUAÇÃO EM EDUCAÇÃO - Forpred, 2017, São Luís. [S. 1.: s. n.].

BALBACHEVSKY, E. A Pós-Graduação no Brasil: novos desafios para uma política bem sucedida. In: SCHWARTZMAN, C. B. S. (org.). Os desafios da Educação no Brasil. Rio de Janeiro: Nova Fronteira, 2005. p. 285-314.

BARRETO, F. C. S.; BORGES, M. N. Novas políticas de apoio à Pós-Graduação: o caso FAPEMIG-CAPES. Ensaio: Avaliação e Políticas Públicas em Educação, Rio de Janeiro, v. 17, n. 65, p. 599-612, out.-dez. 2009. https://doi.org/10.1590/S0104-40362009000400003

BOUFLEUR, J. P. Inserção social como quesito de avaliação da Pós-Graduação. Revista de Educação Pública, Cuiabá, v. 18, n. 37, p. 371-382, maio/ago. 2009. https://doi.org/10.29286/rep.v18i37.488

\section{CAVALCANTE, M. M. S.; GUIMARÃES, M. D.; MENDES, Y. N.} Contribuições do uso do software NVivo em pesquisa no campo da formação de professores. In: CARVALHO, M. V. C.; CARVALHÊDO, J. L. P. (orgs.). Formação e trabalho docente. Teresina: EDUFPI, 2016. v. 3, p. 1-12.

\section{COORDENAÇÃO DE APERFEIÇOAMENTO DE PESSOAL DE NÍVEL} SUPERIOR - Capes. Documento de área: Educação. Brasília, DF, 2016. Disponível em: http://capes.gov.br/images/documentos/Documentos_de_ area_2017/Educa\%C3\%A7\%C3\%A3o.pdf. Acesso em: 20 ago. 2018.

COORDENAÇÃO DE APERFEIÇOAMENTO DE PESSOAL DE NÍVEL SUPERIOR - Capes. Relatório de Avaliação Trienal 2010-2012: Trienal 2013. Disponível em: http://site.ufvjm.edu.br/ppgsasa2/files/2017/02/relatorioavaliacao-2010-2013.pdf. Acesso em 7 set. 2017. 
COORDENAÇÃO DE APERFEIÇOAMENTO DE PESSOAL DE NÍVEL SUPERIOR - Capes. Diretoria de Avaliação. Documento de Área 2013: educação. Disponível em: https://www.capes.gov.br/images/stories/download/ avaliacaotrienal/Docs_de_area/Educa $\% \mathrm{C} 3 \% \mathrm{~A} 7 \% \mathrm{C} 3 \% \mathrm{~A} 3 \mathrm{o}$ _doc_area_e_ comiss\%C3\%A3o_21out.pdf. Acesso em: 5 dez. 2016.

FERREIRA, V. A. (org.). Políticas e avaliação da Pós-Graduação Stricto Sensu: da inserção social local à internacionalização. Brasília, DF: Cátedra UNESCO de Juventude, Educação e Sociedade; Universidade Católica de Brasília, 2018.

HORTA, J. S. B.; MORAES, M. C. M. O sistema CAPES de avaliação da Pós-Graduação: da área de Educação à grande área de ciências humanas. Revista Brasileira de Educação, Rio de Janeiro, n. 30, p. 95-116, set./dez. 2005. https://doi.org/10.1590/S1413-24782005000300008

JEZINE, E.; FERREIRA, L. Expansão e inserção social da Pós-Graduação no Brasil: análise da Região Nordeste. In: CARVALHO, M. V.; CARVALHÊDO, J.; ARAÚJO, F. A.Caminhos da Pós-Graduação no Nordeste do Brasil: avaliação, financiamento, redes e produção científica. Teresina: Edufpi, 2016. p. 191-203.

LAGE, M. C. Utilização do software NVivo em pesquisa qualitativa: uma experiência em EAD. Educação Temática Digital, Campinas, v. 12, nº esp., p. 198-216, mar. 2011. https://doi.org/10.20396/etd.v12i0.1210

RIBEIRO, R. J. Inserção social. 2007. Disponível em: https://www.capes.gov.br/ images/stories/download/artigos/Artigo_23_08_07.pdf. Acesso em: 3 dez. 2016.

SEVERINO, A. J. A política de Pós-Graduação no Brasil: avaliando a avaliação. In: REUNIÃO ANUAL DA ANPED, 26., 2003, Poços de Caldas. Anais][...] Poços de Caldas: ANPEd, 2003.

SGUISSARDI, V. A avaliação defensiva "Modelo Capes de Avaliação": é possível conciliar avaliação educativa com processos de regulação e controle do Estado? In: BIANCHETTI, L.; SGUISSARDI, V. (orgs.). Dilemas da Pós-Graduação. Campinas: Autores Associados, 2009. p.133-176.

VERHINE, R. E.; DANTAS, L. M. V. Reflexões sobre o Sistema de Avaliação da CAPES a partir do V Plano Nacional de Pós-Graduação. Revista Educação Pública, Cuiabá, v. 18, n. 37, p. 295-310, maio/ago., 2009. 


\section{Informações sobre as autoras}

Carlos Eduardo Ferraço: Doutor em Educação pela Universidade de São Paulo. Professor do Programa de Pós-Graduação em Educação da Universidade Federal do Espírito Santo. Líder do grupo de pesquisa Currículos, cotidianos, culturas e redes de conhecimentos. Bolsista de Produtividade de Pesquisa do Conselho Nacional de Desenvolvimento Científico e Tecnológico. Contato: ferraco@uol.com.br / ferraco1597@gmail.com

iD http://orcid.org/0000-0002-4019-591X

Isabel Maria Sabino de Farias: Doutora em Educação Brasileira pela Universidade Federal do Ceará. Professora do Centro de Educação e do Programa de Pós-Graduação em Educação da Universidade Estadual do Ceará. Líder do grupo de pesquisa Educação, cultura escolar e sociedade (Educas/Conselho Nacional de Desenvolvimento Científico e Tecnológico). Coordenadora do Observatório Desenvolvimento Profissional Docente e Inovação Pedagógica. Contato: isabel.sabino@uece.br.

iD https://orcid.org/0000-0003-1799-0963 